\title{
Facilitadores e Barreiras Percebidos por Pessoas com Cegueira Congênita para a Prática de Atividade Física ${ }^{1}$

\author{
How Persons with Congenital Blindness Perceive Facilitators and \\ Barriers for the Practice of Physical Activities
}

\author{
Fabiane Frota da Rocha MORGADO ${ }^{2}$ \\ Angela Nogueira Neves Betanho CAMPANA ${ }^{3}$ \\ Jairo José Monteiro MORGADO 4 \\ Leonardo de Sousa FORTES 5 \\ Maria da Consolaçáo Gomes Cunha Fernandes TAVARES ${ }^{6}$
}

\begin{abstract}
RESUMO: a prática de atividade física é um importante elemento para um estilo de vida saudável. Entretanto, entre pessoas com deficiência visual, esta prática pode ser reduzida, o que torna este grupo suscetível ao desenvolvimento de patologias associadas à inatividade física. Este estudo teve por objetivo investigar facilitadores e barreiras percebidas por pessoas com cegueira congênita para a prática de atividade física. Foram realizados dois grupos focais com onze sujeitos adultos com cegueira congênita, sendo seis mulheres e cinco homens, com idade média de 34 anos ( \pm 7 anos). A análise de conteúdo foi utilizada para interpretar os dados. Duas grandes categorias foram apresentadas nos resultados, classificadas como "principais facilitadores para a prática de atividade física" e "principais barreiras para a prática de atividade física". Os facilitadores (família, professores de Educação Física especializados, instituição especializada, materiais adaptados, e reconhecimento dos benefícios) e as barreiras (família, professores de Educação Física despreparados, limitada infraestrutura em centros de atividade física, sentimentos de exclusão em aulas de Educação Física, dificuldade na habilidade espacial e na coordenação motora) apontados pelos participantes mostraram-se complexos e multifacetados, de ordem social, ambiental e pessoal. Considerando os benefícios da atividade física, é fundamental que os profissionais da área adaptem estratégias de inclusão adequadas à participação de pessoas que não enxergam, possibilitandolhes explorar diferentes possibilidades de movimento na sua relaçáo com o mundo, as quais poderiam atuar positivamente em seu desenvolvimento biológico, psicológico e social.
\end{abstract}

PALAVRAS-CHAVE: Educação Especial. Inclusão. Estilo de vida sedentário. Pessoas com Deficiência Visual.

\begin{abstract}
The physical activity is an important element for a healthy lifestyle. However, among people with visual impairments, this practice is reduced, which makes this group as being at risk for developing diseases associated with physical inactivity. This study aims to investigate facilitators and barriers perceived by persons with congenital blindness to physical activity. Two focus groups were conducted with eleven subjects with congenital blindness, six female and five male, age mean 34 years $(+7$ years). The results showed two broad categories: "main facilitators to physical activity" and "main barriers to physical activity". The facilitators (family, specialist Physical Education teachers, adapted materials, and recognition of the benefits) and barriers (family, unprepared Physical Education teachers, limited infrastructure in physical activity centers, feelings of exclusion in Physical Education classes, difficulty in spatial ability and motor coordination) reported by participants were complex and multifaceted, with social, environmental and personal origins. Considering the benefits of physical activity, it is essential that professionals adapt strategies for inclusion and appropriate participation of the congenitally blind, enabling them to explore different possibilities of movement and relationship to the world, which may act positively on the biological, psychological and social development.
\end{abstract}

KEYWORDS: Special Education. Inclusion. Sedentary Lifestyle. Persons with Visual Impairment.

\footnotetext{
${ }^{1}$ Agradecimento: FAPESP (Processo 2010/50684-5).

${ }^{2}$ Doutora. Universidade Estadual de Campinas, Faculdade de Educação Física, Departamento de Atividade Física Adaptada. fabi. frm@hotmail.com

${ }^{3}$ Doutora - Docente na Universidade Sagrado Coração, Departamento de Ciências da Saúde. angelanneves@yahoo.com.br

${ }^{4}$ Doutorando pela Universidade Estadual de Campinas, Faculdade de Educação Física, Departamento de Atividade Física Adaptada. jairomorgado@bol.com.br

${ }^{5}$ Doutorando em Psicologia (UFJF). Professor Auxiliar do Núcleo de Educação Física e Ciências do Esporte - Centro Acadêmico de Vitória (UFPE). leodesousafortes@hotmail.com

${ }^{6}$ Professor titular. Universidade Estadual de Campinas, Faculdade de Educação Física, Departamento de Atividade Física Adaptada.mcons@fef.unicamp.br
} 


\section{InTROdUÇÃo}

A prática de atividade física tem sido apontada como precursora e mantenedora de inúmeros benefícios físicos e mentais (PENEDO; DAHN, 2005; SÖDERGREN et al., 2008), apresentando um documentado efeito positivo sobre a redução de mortalidade, níveis de adiposidade, prevenção de diabetes e de doenças cardiovasculares (JANSSEN; LeBLANC, 2010; SÖDERGREN et al., 2008). Ao contrário, a inatividade física - ou estilo de vida sedentário - dobra os riscos à saúde, especialmente, aqueles relacionados à hipertensão, a alguns tipos de câncer, ao fumo e à obesidade (PENEDO; DAHN, 2005). Pode, ainda, aumentar os riscos para mortalidade prematura (KOBBERLING; JANKOWSKI; LEGER, 1989).

Em sujeitos com deficiência visual, o índice de atividade física tem sido apontado como significantemente menor do que em videntes, o que pode tornar este grupo suscetível ao desenvolvimento de patologias relacionadas à inatividade física (KOBBERLING; JANKOWSKI; LEGER, 1989; HOLBROOK et al., 2009). Kakiyama, Koda e Matsuda (1999) e Holbrook et al. (2009) afirmam que a capacidade aeróbica de pessoas com deficiência visual é mais baixa quando comparada a pessoas videntes; e que as pessoas com deficiência visual são mais obesas do que pessoas videntes. Kozub e Oh (2004) observam que o nível diário de atividade física de crianças e adolescentes com deficiência visual é menor do que aquele de seus pares videntes.

Fatores ambientais são apontados por De Potter (2006) como uma das maiores barreiras que as pessoas com deficiência visual podem encontrar para prática de atividade física. Para o autor, as pessoas com cegueira necessitam de uma gama de informaçóes na realização desta prática, tais como: informaçóes auditivas, táteis, sobre distância, direção, profundidade, as quais nem sempre são adequadamente disponíveis em seu ambiente. Ambientes pobres de estímulos dificultam o interesse da pessoa com deficiência visual para a prática de atividade física. Ao contrário, ambientes adaptados possibilitam a esta explorar suas diferentes habilidades de movimento. A questão central, segundo o autor, pauta-se nas condiçóes ambientais e não no comprometimento visual, sendo fundamental a adaptação de materiais e estratégias para possibilitar ao sujeito com cegueira a prática de atividade física.

Em complemento, Ardito e Roberts (2007) destacam que fatores sociais podem ser considerados barreiras para que a criança com deficiência visual experiencie diferentes atividades físicas. Os autores esclarecem que pais superprotetores podem restringir possibilidades de movimento de seus filhos com cegueira. De igual modo, professores de Educação Física que não acreditam no potencial de seus alunos com cegueira para participar de brincadeiras que envolvem atividade física podem atuar como obstáculos para que estes usufruam das atividades propostas em aula.

Considerando o positivo impacto da atividade física na saúde e, portanto, na promoção de qualidade de vida, torna-se essencial conhecer as percepçóes de pessoas com deficiência visual em relação a estas atividades. Entretanto, são escassas as informações disponíveis na literatura a este respeito (RIMMER et al., 2004). O conhecimento de facilitadores e barreiras potenciais que afetam a participação de pessoas com deficiência visual em atividade física poderia providenciar informaçóes importantes e necessárias para o desenvolvimento de intervençóes consistentes. Estas informaçóes poderiam ser utilizadas tanto por professores de Educação Física quanto por 
outros profissionais que atendem pessoas com deficiência visual, tornando-lhes possível adotar diferentes estratégias de atividade física adaptada.

Diante do pressuposto, este estudo objetivou investigar facilitadores e barreiras percebidas por pessoas com cegueira congênita para a prática de atividade física.

\section{MÉTodo}

Esta investigação é do tipo qualitativa descritiva. Seu início deu-se após sua aprovação pelo Comitê de Ética em Pesquisa da Universidade Estadual de Campinas, conforme parecer no: 187/2010, aprovado na data de 15/04/2010.

\subsection{Sujeitos}

A amostra foi composta por 11 sujeitos com cegueira congênita, cinco homens e seis mulheres, com idade entre 26 e 48 anos (média: 34,8/desvio padrão: 7,34), revisores Braille e professores do Instituto Benjamin Constant (IBC) - Rio de Janeiro (RJ). Foram adotados quatro critérios de inclusão: ter nascido com a cegueira ou a manifestado até os cinco anos de idades, possuir mais de 18 anos de idade, estar vinculado ao IBC e aceitar participar voluntariamente da pesquisa.

\subsection{Procedimentos de coleta de dados}

Os dados foram coletados com a técnica do Grupo Focal, comumente utilizada com a finalidade de obter, mediante trocas realizadas no grupo, atitudes, conceitos, sentimentos, crenças, experiências e reaçóes a respeito de um determinado tema (MORGADO; CAMPANA; TAVARES, 2012).

Dois grupos focais foram realizados. No primeiro, houve a participação de seis mulheres. No segundo, cinco homens. Ambos os grupos tiveram a presença de quatro pesquisadores, sendo dois deles os moderadores da reuniâo, um deles atuou como observador e o outro filmou toda a reuniáo do grupo focal. As duas reunióes ocorreram em dias distintos e cada uma delas teve duração aproximada de 100 minutos.

O Termo de Consentimento Livre e Esclarecido (TCLE) foi disponibilizado em Braille aos participantes. A assinatura deste termo pôde ser realizada em tinta ou em digital, dependendo da vontade dos participantes.

A respeito da prática de atividade física, três questōes foram realizadas: "Algum de vocês pratica ou já praticou atividade física? O que mais os facilita ou facilitava durante a prática de atividade física? O que mais os dificulta ou dificultava durante a prática?" Os participantes discutiram, concordaram, discordaram e colocaram seus pensamentos e opinióes em diferentes caminhos.

\subsection{ANÁLISE DOS DADOS}

O material da gravação dos dois grupos focais foi transcrito na íntegra. Estes dados foram analisados com a técnica de Análise de Conteúdo (BARDIN, 1977). Todas as três 
etapas da análise proposta por Bardin (1977), que constam de a) pré-análise - compreende leitura flutuante, organização do material, sua operacionalização e sistematização, escolha dos documentos analisados e elaboração de indicadores; b) exploração do material - fase longa e exaustiva, que exige o trabalho de uma equipe, na qual seus membros atuam como juízes do trabalho de codificação e classificação temática, sendo que, neste estudo, dois juízes participaram desta etapa; e c) tratamento dos resultados, inferência e interpretação - envolve a tabulação e aplicação de técnicas descritivas de análise, foram rigorosamente seguidas.

Durante estas três etapas, o material da transcrição foi lido exaustivamente dando origem a categorias, configurando, portanto, a análise de conteúdo categórica. As categorias foram agrupadas conforme temas que guardavam semelhança entre si, configurando, desse modo, a técnica de análise de conteúdo temática.

\section{Resultados E discussáo}

Esta investigação teve por finalidade investigar facilitadores e barreiras percebidas por adultos com cegueira congênita para a prática de atividade física. Para nosso conhecimento, não foram encontrados estudos prévios que abordassem esta problemática, o que impossibilita a comparação dos resultados obtidos nesta pesquisa.

Entre pessoas com deficiência física, um estudo prévio investigou os facilitadores e barreiras para a prática de atividade física. Por meio da realização de quatro grupos focais, Rimmer et al. (2004) encontraram que o nível de participação em atividade física por estas pessoas era complexo e multifatorial. Os autores identificaram dez temas principais: 1) estrutura arquitetônica; 2) econômica; 3) emocional e psicológica; 4) equipamentos; 5) interpretação de diretrizes, códigos, regulamentos e leis; 6) informação; 7) questões de educação, treinamento e especialização de profissionais; 8) percepçóes e atitudes de pessoas que não são deficientes, inclusive profissionais; 9) políticas ou procedimentos internos; e 10) recursos de acessibilidade.

De igual modo, este estudo aponta que, para os participantes com cegueira congênita, os facilitadores e barreiras encontram-se focados em aspectos abrangentes e multifacetados, que abordam questóes de cunho pessoal, social e ambiental. Esta discussão será realizada a partir de duas grandes categorias formadas nesta pesquisa: a) principais facilitadores para a prática de atividade física e b) principais barreiras para a prática de atividade física.

\section{a) Principais facilitadores para a prática de atividade física}

Os principais facilitadores são apontados em cinco caminhos principais, de ordem social, ambiental e pessoal: 1) família, 2) professores de Educação Física especializados, 3) instituição especializada, 4) materiais adaptados e 5) reconhecimento dos benefícios, conforme demonstra a Figura 1. 


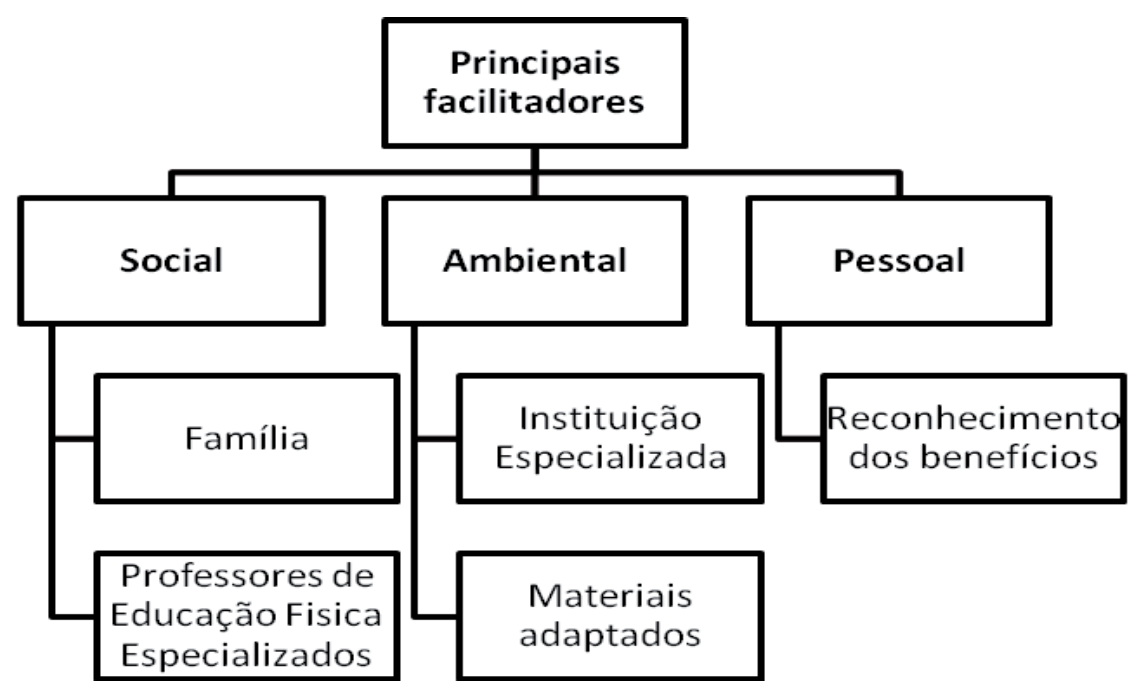

Figura 1 - Facilitadores percebidos por pessoas com cegueira congênita para a atividade física. Fonte: Elaboração própria (2012).

A família pode representar na vida da pessoa com cegueira congênita uma importante fonte de apoio e incentivo para que a criança que náo enxerga se interesse por suas primeiras experiências de atividade física. Ao relatarem suas vivências de atividade física durante a infância, os participantes deste estudo apontaram a família como um elemento facilitador desta prática, eis alguns exemplos:

Aprendi muito com o meu pai. Mas, era assim... nunca a atividade fisica foi uma coisa direcionada mesmo: - Agora, você vai ter que fazer essa atividade fisica, porque vai ser bom para a tua saúde. Era mais uma coisa de: - Ah, vamos fazer isso? Meu pai falava: Ah, vamos aprender a nadar? Então, eu nadei. (participante 8) [sic]

A respeito do papel da família no desenvolvimento de senso de competência da criança com cegueira para sua exploraçáo do meio, Lambert e West (1980) esclarecem a importância dos cuidadores adotarem uma atitude responsiva às necessidades da criança. Ou seja, é necessário que estes sejam disponíveis às necessidades de seus filhos com cegueira, oferecendo-lhes suporte e encorajando-os a explorar e manipular o ambiente, respondendo aos seus desejos e oferecendo estímulos motivacionais, o que irá lhes proporcionar a oportunidade de experimentar suas primeiras sensaçóes de competência em sua relação com o mundo. Ao contrário, de acordo com os autores, os cuidadores que superprotegem a criança que não enxerga, restringindo a exposição desta ao ambiente e limitando a oportunidade de exploraçáo do meio, podem ocasionar na criança o desenvolvimento de senso de incompetência diante das atividades de seu cotidiano, além de desenvolver sérios transtornos psíquicos na vida adulta, como a depressão.

Ressalta-se a relevância central da família em oferecer um ambiente propício para que a pessoa com cegueira sinta-se segura e confiante em suas habilidades de explorar diferentes tipos de atividades físicas, usufruindo dos prazeres que esta oferece. 
A iniciação ao esporte com professores de Educação Física especializados foi outro aspecto facilitador da prática de atividade física destacado pelos participantes deste estudo. De acordo com eles, estes professores encontram-se preparados para oferecer um atendimento de qualidade às suas necessidades.

Ai eu vim parar no IBC e as coisas aqui já são bem mais fáceis! Até porque a gente brinca entre a gente, tem as mesmas dificuldades. Porque foi assim que a gente começou a brincar, sem orientação direta, né, que a gente brincava naquele gramado ali, naquele pátio enorme inclusive, mas que é uma maravilha. Depois, fui iniciado na Educação Física por professores já especializados e isso, é claro, me facilitou muito, mas, muito mesmo! (participante 8) [sic]

Eu gostava daqui (IBC), porque o professor ele procurava frisar, mostrar, fazer, repetir bastante pra gente pegar bem os movimentos, né! Pra gente, é mais dificil isso, porque a gente não está vendo. Ele tinha que ir em cada um pra mostrar: - Oh a perna vai aqui, bota a sua perna esquerda aqui. Ele botava onde tinha que estar, então, aquilo ali com o tempo já passava a ser natural... Mas, assim, no inicio, por exemplo, o rolamento lateral, né, era um dificuldade pra mim, mas depois... ele me mostrou, fez comigo, dai aquilo já se tornou natural (participante 7) [sic]

Os professores de Educação Física daqui (IBC) já tinham esse preparo, então, desde pequeno, eu já fui iniciado com a natação. Nataçâo, pra mim, foi tranqüilo. Aqui, no Benjamim, eu conheci quase tudo, porque eu fiz quase tudo. Eu fiz judô, en fiz natação, eu fiz atletismo, então, eu fui conhecendo tudo e o lado bom que eu fui conhecendo, já com essas pessoas preparadas, então, isso facilitou bastante mesmo. (participante 9) [sic]

Estes relatos demonstram, portanto, duas questôes principais. A primeira refere-se aos professores de Educação Física. Observa-se que a atuação eficaz de professores especializados, pautada, sobretudo, na crença de que seus alunos com cegueira são capazes de realizar diferentes atividades, fez diferença na motivação destes para a prática de atividade física. Ao crer na capacidade de seus alunos, estes professores podem buscar a criação e/ou adaptação de estratégias fundamentais para a inclusão dos alunos que não enxergam em suas aulas.

A segunda questão refere-se à instituição especializada. Percebe-se uma atribuição positiva dada ao Instituto Benjamin Constant (IBC) pelos participantes. A referida instituição foi apontada como um lugar facilitador de suas primeiras experiências com a atividade física. Observa-se que tanto a estrutura arquitetônica/ambiental do IBC (pátio grande, gramado, piscina, pista de atletismo, sala de judô, entre outros aspectos), quanto a possibilidade de um atendimento quase que personalizado dos professores que lá atuam, configuram um ambiente facilitador das primeiras experiências corporais dos participantes que frequentaram esta Instituição.

Seabra Júnior e Manzini (2008) chamam atenção que o estilo de ensino adotado é fator essencial para motivação, aprendizagem, feedback e sucesso do aluno na atividade física proposta. Não obstante, os autores destacam que, embora o atendimento mais individualizado seja uma forma de favorecer a aprendizagem, este não é sempre possível, principalmente em ambientes inclusivos, em que se trabalha com diversidade de alunos e em número elevado. Neste contexto, torna-se fundamental ao professor de Educação Física adequar suas estratégias de ensino de modo a possibilitar às pessoas com cegueira um papel ativo no processo de aprendizagem, por meio de soluçóes de problemas, experimentaçóes e autodescobertas, seja em instituição especializada ou inclusiva. 
Outro facilitador percebido pelos participantes diz respeito à existência de materiais adaptados. Batista (2005) destaca que estes materiais podem representar elementos do mundo, necessários para a formação de conceitos e para o processo de escolarização. As adaptaçóes podem indicar formas, texturas, distâncias relativas, incidência de luz, entre outros fenômenos, que possibilitam ao sujeito com cegueira participar de concepçóes comuns de sua cultura. Entretanto, a construção de materiais adaptados pode ser um desafio para o professor, por exigir criatividade e motivação para a adaptaçáo, já que existe um número limitado de materiais adaptados disponíveis.

No contexto da atividade física, a adaptação de materiais pode ser diversificada, incluindo: bolas com guizos em seu interior; bolas envolvidas com sacolas plásticas ou com jornal e fita crepe; bolas de diferentes texturas, tamanhos e pesos; pneus (bicicleta, carro e caminhão); cordas; jornais; caixas de papelão; garrafas plásticas; latas; bolas de meia, e tantos outros materiais que a criatividade do professor possibilitar (SEABRA JÚNIOR; MANZINI, 2008; SOLER, 2005). Estes materiais podem ser construídos com os próprios alunos, visando despertar o interesse do sujeito, possibilitando-lhe diversidade em suas experiências corporais. Os relatos dos participantes abaixo destacam a importância dos materiais adaptados como facilitadores da prática de atividade física:

O futebol foi muito interessante, porque a gente aprendeu muito aquele negócio de botar a sacolinha na bola. Antigamente, inclusive, a maior coisa que tinha que conseguir era ficar pedindo sacos para as pessoas para colocar na bola... (participante 7) [sic]

[...] eu tinha facilidade, que era, por exemplo, a bola. Eu gostava de jogar muito, então, eu tinha uma facilidade incrivel!' A gente botava saco na bola e jogava em todo intervalo. (participante 8) [sic]

Finalmente, o reconhecimento dos benefícios advindos da prática de atividade física foi apontado pelos participantes como facilitadores e impulsionadores da busca por uma vida mais ativa fisicamente, conforme relato dos participantes 2 e 7, respectivamente.

Hoje eu faço (atividade física) por um bem estar, não porque eu também goste, eu não gosto destas coisas não! Mas, o bem estar dela é sensacional! Por isso mesmo, me motiva. [sic]

O esporte te dá uma orientação espacial incrivel! O futebol te dá um reflexo muito bom! Por exemplo, às vezes, eu já passei por situaçōes que tinha um pouco de rejeição à bengala. Já teve dias que eu voltava pra casa sem a bengala e conseguia desviar de coisas sem tá enxergando, mas somente pelo reflexo do futebol. Porque, no futebol, a gente tem que correr, não adianta um cara que tem medo de correr, de trombar, querer fazer futebol, que ele não vai fazer. Ele tem que correr, e quando a gente corre no futebol, não é aquela corrida sem reflexo, que você não sabe onde vai chegar, não sabe que vai bater... É lógico que tem as trombadas como tem também num jogo normal, mas você tem aquela sensação... você consegue perceber, pô, tem alguma coisa na minha frente. Você não identifica o que é, mas você sabe que tem! [sic]

Frente a estes relatos, é possível observar uma associação positiva realizada pelos participantes entre a atividade física e diferentes benefícios oriundos dela, quais sejam: bem estar, orientação espacial em atividades da vida diária, facilidade de locomoção e de desvio de objetos. Çolak et al. (2004) reportam que a prática de atividade física por pessoas com deficiência visual pode ser considerada uma opção efetiva para melhorar as habilidades motoras 
destes sujeitos. Ardito e Roberts (2007) salientam que esta prática proporciona a aquisição de habilidades espaciais e de uma vida mais confortável, com níveis aumentados de autoestima. $\mathrm{O}$ reconhecimento destes benefícios pelos participantes com cegueira congênita apresentou-se neste estudo como um importante fator motivacional.

\section{b) Principais barreiras para a prática de atividade física.}

Seis barreiras de cunho social, ambiental e pessoal são destacadas pelos participantes: 1) família, 2) professores de Educação Física despreparados; 3) limitada infraestrutura em centros de atividade física, 4) sentimento de exclusão em aulas de Educação Física, 5) dificuldade na habilidade espacial, e 6) dificuldade na coordenação motora. A Figura 2 sintetiza estes achados.

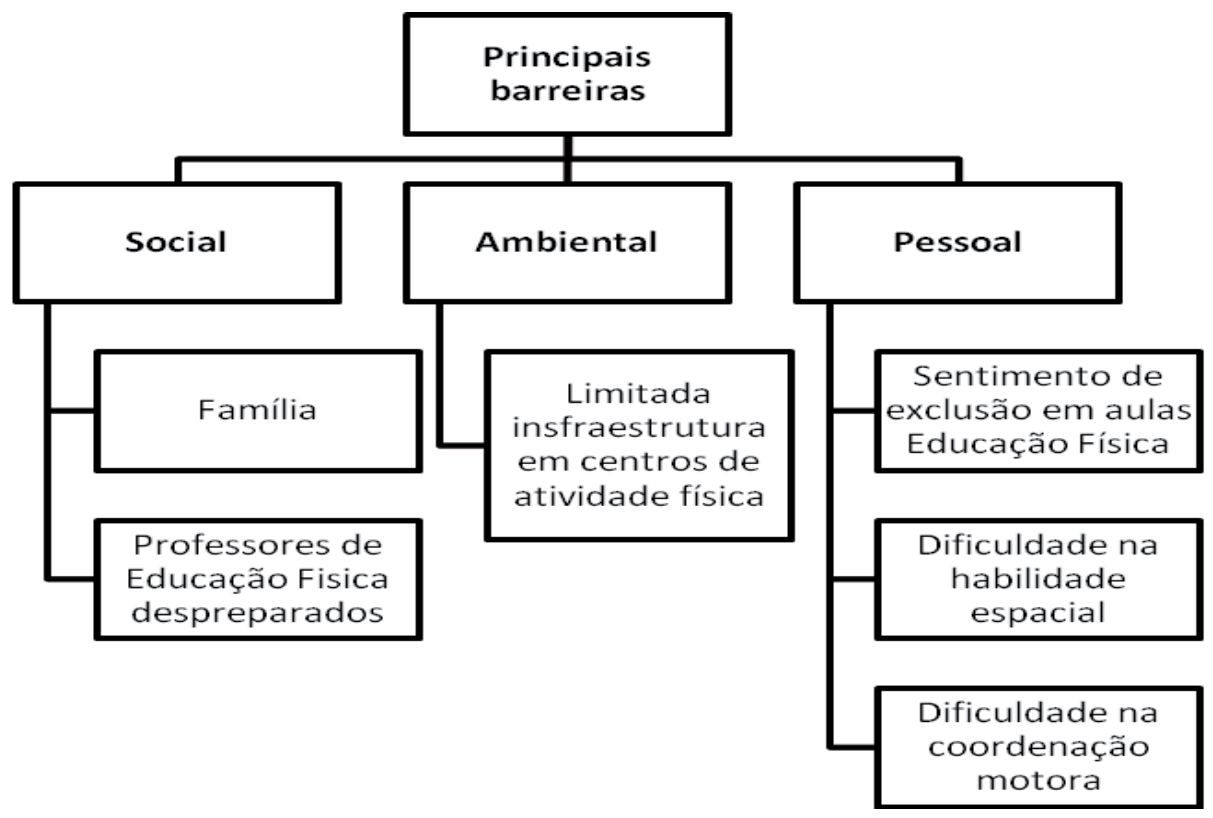

Figura 2 - Barreiras percebidas por pessoas com cegueira congênita para a atividade física. Fonte: Elaboraçấo própria (2012).

A respeito da família e dos professores de Educação Física despreparados, o relato do participante 8 servirá como suporte para a discussão que se sucede:

Quando eu estava na quarta série, eu pensei assim: - Bom, eu vou! (para a aula de Educação Física). $A i$, eu fui. Ai, a minha mãe inventou de ir também: - Ah, eu vou com você. Aí, ela foi. Ai, quando chegou lá, eu imaginei que alguma coisa eu pudesse fazer, mesmo que eu não fosse jogar bola. $O$ professor de Educação Física poderia muito bem ter me servido alguma coisa né, alongamento... A minha mãe, quando viu o pessoal lá na quadra, todo mundo, ela disse: - Ah, não, você não pode fazer isso, de jeito nenhum! E me levou de volta, sabe? De volta... Eu não podia fazer nada, eu não sabia me locomover, sozinho ali... E isso para mim foi uma coisa extremamente humilhante, porque, pô, o professor, todo mundo vê aquilo, eu voltando... Eu gostaria de estar num lugar onde eu náo tivesse que passar por uma humilhação dessas... Então, pra você vê, eu, em todo o ensino fundamental, no ensino médio, eu nunca fiz nenhuma atividade fisica! [sic] 
O valor dos pais colocados sobre a atividade pode influenciar sobremaneira as atitudes de seus filhos. Os pais que acreditam no sucesso de seus filhos durante a prática física tendem a ser importantes fatores motivacionais no encorajamento destes para uma vida mais ativa fisicamente. Não obstante, as percepções de alguns pais, tais como a crença de que a criança não possui habilidade para ser fisicamente ativa, a possibilidade de que seus filhos se machuquem, a ausência de atividades disponíveis para a criança, entre outras, podem se tornar obstáculos para que seus filhos participem de atividades físicas. Deste modo, torna-se fundamental que os pais sejam "educados" sobre as diferentes possibilidades de adaptar atividades para as crianças com deficiência visual, visando propiciar a estas oportunidades para a adoção de um estilo de vida saudável (STUART; LIEBERMAN; HAND, 2006).

No mesmo sentido, os professores de Educação Física possuem um papel fundamental na adesão da pessoa com cegueira congênita às suas aulas. Para algumas crianças, sua primeira exposição para a prática de atividade física pode ser nas aulas de Educação Física, onde há possibilidades distintas de exploração de diferentes tipos de movimentos. Todavia, há registro de que algumas crianças com deficiência visual não participam das aulas de Educação Física ou de esportes extracurriculares. Em alguns casos, esta falta de participação reflete a inexperiência de alguns professores de incluir as crianças com deficiência em suas aulas (STUART; LIEBERMAN; HAND, 2006). A questão, portanto, não estaria associada ao comprometimento visual, mas ao resultado do comportamento desencorajador de alguns professores de Educação Física que não se esforçam para que seus alunos com cegueira tenham oportunidades favoráveis para participar das atividades propostas (WINNICK, 1985).

$\mathrm{Na}$ pesquisa realizada por Stuart, Lieberman e Hand (2006), foram apontados alguns motivos pelos quais os professores de Educação Física sentem dificuldade de incluir crianças que não enxergam em suas aulas, quais sejam: medo sobre a segurança das crianças; prioridade colocada sobre serviços especializados como orientação e mobilidade, e dificuldade no entendimento da importância da atividade física para estas crianças. Silva, Duarte e Almeida (20011) demonstraram a concepção de professores de Educação Física a respeito da participação de alunos com deficiência visual em suas aulas, apontando: a) ausência de capacitação profissional para atender as necessidades deste público b) problemas estruturais, que dificultam a participação dos alunos deficientes visuais e c) concepção dos professores de que seus alunos são limitados devido à deficiência visual.

Destacando a complexidade desta questão, que envolve desde a formação do professor até o processo de educação continuada, urge destacar a necessidade de ampliar a capacitação dos professores de Educação Física para o atendimento do aluno com deficiência visual. Esta questão é particularmente importante porque, de acordo com Ponchillia et al. (1992), na medida em que a criança com deficiência visual possui oportunidade de participar em atividade física regular, ela exibe níveis de condicionamento físico semelhantes com aqueles de crianças videntes. Ademais, crianças que engajam em atividade física regular são mais propensas a se tornarem adultos com um estilo de vida mais ativo (HOLBROOK et al., 2009). Portanto, torna-se fundamental que o professor de Educação Física esteja preparado para adotar efetivamente atitudes sólidas e inclusivas em suas aulas. 
Sob uma perspectiva ambiental, algumas academias de ginástica parecem não serem adequadas para receberem pessoas com cegueira. A limitada infraestrutura em centros de atividade física foi apontada pelos participantes como mais uma barreira para uma vida fisicamente ativa. O relato da participante 2 suporta esta afirmação.

Lá na Tijuca tem uma academia que tem musculação: - Ih vou fazer aqui, pertinho de casa. Só que eu não fui bem aceita na academia, não. Ai eu senti uma discriminação. Porque eu cheguei e expliquei, falei: - Olha quero fazer academia, porém eu preciso de um professor para me auxiliar. E a academia náo ofereceu o professor, porque, segundo eles, eles estariam me oferecendo um personal training, e eles não podem me oferecer um personal training. Falei: - Olha eu não quero um personal, eu quero alguém para me auxiliar a deslocar de um aparelho pro outro, me ajudar a colocar o peso. Ah, mas esse serviço a gente não pode oferecer. Ou seja, eu entendi que, lá, pra mim, não tem espaço, nem se quer me deram a abertura de tentar. (participante 2) [sic]

Resultados semelhantes foram encontrados no estudo de Rimmer et al. (2005). Na investigação descritiva e exploratória realizada pelos autores em 35 academias de ginástica, foram identificadas várias áreas que poderiam ser de difícil acesso para pessoas com deficiência visual. Dentre estas, destacam-se: reduzida disponibilidade de equipamentos adaptados; de sinais sonoros nos elevadores e de informaçóes disponíveis em Braille, as quais, quando utilizadas aumentam os custos.

Neste sentido, percebe-se a necessidade de reestruturação na política de atendimento destes estabelecimentos. A abrangência desta reestruturação deve considerar, além da mudança de atitude dos profissionais que recebem pessoas com deficiência, alteraçóes também nos espaços físicos e sociais (incluindo política de atendimento inclusiva, estrutura arquitetônica adaptada, especialização dos profissionais, adaptação de equipamentos, entre outras). Desta forma, poderia ser possível ampliar o acesso do público com deficiência visual a estes recintos.

De cunho pessoal, o sentimento de exclusão nas aulas de Educação Física durante a infância foi indicado pelos participantes como uma barreira à prática de atividade física. Achados semelhantes foram encontrados no estudo de Stuart, Lieberman e Hand (2006), realizado com crianças com cegueira. $\mathrm{Na}$ concepção destas, dentre as principais barreiras para a prática encontra-se o sentimento de não ter ninguém para realizar a atividade. $O$ relato seguinte demonstra as sensaçóes de um participante relacionadas à sua infância, quando perdeu a visão, momento no qual sentiu-se excluído das atividades.

Eu passei por umas fases realmente interessantes, primeiro porque eu nasci com baixa visäo, baixíssima. Com três ou quatro anos, eu morava num local tranquilo, então, eu brincava com os meninos de bola, tinha lá as dificuldades, eu era sempre o último a ser escolhido no time, no pique, enfim, essas coisas que não tem jeito! Mas eu sempre brinquei e tal. Com cinco anos, eu perdi a visão total, então, eu já comecei a ser excluido! Até mesmo na escola, nas aulas de Educação Física. (participante 10) [sic]

Stuart, Lieberman e Hand (2006) comentam que, em estabelecimentos educacionais, crianças videntes podem expressar hesitação em interagir com crianças que possuem deficiência visual. Adicionalmente, destacam ser muito comum que crianças com deficiência visual evitem a prática de atividade física por medo de se sentirem chacoteadas. O profissional de Educação Física deve estar atento a estas questóes, no sentido de saber intermediar os conflitos que podem 
emergir deste contexto, proporcionando à criança com cegueira, um ambiente propício para interação social e exploração de suas diferentes possibilidades de movimentos corporais.

A dificuldade na habilidade espacial foi outra questão reportada como barreira para a prática de atividade física. Este tipo de habilidade é a locomoção eficientemente do sujeito de um lugar para outro no espaço. Pode ser adquirida por meio de memorização de rotas fixadas entre os diferentes lugares ou por meio de mapas espaciais cognitivos, que é a representação que possibilita informaçóes sobre a localização de um objeto relativa a outro, incluindo distância e ângulo de informação (MORRONGIELLO, et al., 1995). Os relatos seguintes destacam as percepçóes dos participantes a respeito da habilidade espacial:

Também tem outra coisa, se a pessoa não tem noção espacial, aí, ela vai, a toda hora, está esbarrando num colega. Então, isso atrapalha ela, fazendo ela se sentir desmotivada e aquele colega que está ali, ele vai acabar achando ela chata! (participante 1) [sic]

Na musculação, por mais que a gente conheça o espaço, não tem como você está se deslocando de um aparelho pro outro sozinha. Mesmo você conhecendo o espaço. Porque seu colega náo tem a obrigação de saber que você é cego. E no que você coloca a máo você pode colocar a mão num aparelho, num colega que está fazendo um exercício, então, pode acabar se machucando por conta disso. (participante 2) [sic]

Algumas observaçóes sistemáticas apontam que os sujeitos com cegueira congênita apresentam menores performances em habilidades espaciais do que videntes e assumem a premissa de que a ausência da experiência visual desde idades precoces dificulta a integração de informaçóes do ambiente, importante para a realização de tarefas espaciais (ARDITI; HOLTZMAN; KOSSLYN, 1988; BIGELOW, 1991; BIGELOW, 1996, FIEHLER; REUSCHEL; RÖSLER, 2009; NOORDZIJ; ZUIDHOEK; POSTMA, 2007; VECCHI, 1998). Nesta vertente teórica, há uma valorização do canal visual em detrimento de outros canais sensórios, destacando-se que, para pessoas com cegueira congênita, a conquista das habilidades espaciais possui atraso se comparadas àquelas videntes (THINUS-BLANC; GAUNET, 1997).

Contudo, esta teoria é questionada no estudo de Ungar, Blades e Spencer (1996). Na revisão de literatura realizada pelos autores, constatou-se que, embora a maioria das pesquisas revelasse que crianças com cegueira congênita possuíam um desempenho pior em habilidades espaciais quando comparadas aquelas videntes, a visão não era um requisito obrigatório para estas habilidades. As crianças que náo enxergam desde idades precoces podem utilizar outras estratégias para decodificar informaçóes espaciais do ambiente, como aquelas provindas do estímulo tátil, auditivo, olfativo e cinestésico, apresentando bom desempenho em suas habilidades espaciais.

Neste contexto, torna-se fundamental que os profissionais de Educação Física fiquem atentos a esta questão e propiciem condiçóes favoráveis para que as habilidades espaciais de pessoas com cegueira sejam plenamente desenvolvidas. Esta questão é particularmente importante na medida em que as habilidades espaciais são elementos necessários não somente para a prática de atividade física, mas, sobretudo, para outros aspectos da vida do sujeito, como na orientação e mobilidade (SEABRA JÚNIOR; MANZINI, 2008). 
Por fim, foram identificadas barreiras em relação à coordenação motora. Este tipo de coordenação é a capacidade de usar de forma acurada e consistente os músculos esqueléticos, resultando em uma ação global mais eficiente, plástica e econômica. Este tipo de coordenação possibilita o domínio do corpo no espaço, por meio do controle dos movimentos mais rudes (PLANINSEC; PISOT, 2006). Os relatos abaixo demonstram as dificuldades percebidas pelos participantes em relação a este aspecto:

Tô descobrindo que eu nem tenho coordenação motora. Eu pensei que tivesse! Esse negócio de: abre o braço e fecha a perna - abre a perna e fecha o braço! E ainda por cima contando junto com tudo isso. Rapaz, é doido! (participante 2) [sic]

Possíveis explicações para esta dificuldade podem ser encontradas nos estudos de Adelson e Fraiberg (1974), Santin e Simmons (1977), Murphy e O’Driscoll (1989) e Brambring (2006), os quais apontam atrasos no desenvolvimento da coordenação motora de crianças com cegueira quando comparadas com crianças videntes. Ochaita e Rosa (1995) atribuíram este fato ao desconhecimento que estas crianças têm da existência dos objetos que não podem ver e alcançar com os braços e pela consequente falta de interesse pelo mundo exterior.

Todavia, conforme esclarecem Lopes, Kitadai e Okai (2004), é possível minimizar as alterações que a ausência da visão pode provocar no controle e desenvolvimento motor. Programas terapêuticos adequados podem auxiliar no desenvolvimento da coordenação motora de crianças com cegueira por meio de experiências sensoriais distintas (brincar de balanço; aviãozinho; equilibrar-se sobre rolo, caixas, bola; descer e subir escadas; caminhada sobre solos instáveis, driblar obstáculos através de circuitos, entre outras) que podem ser oferecidas à criança durante seu desenvolvimento.

\section{Conclusóes}

Este estudo apontou os principais facilitadores e barreiras percebidas por pessoas com cegueira congênita para a prática atividade física. Os resultados destacaram um complexo multifacetado de aspectos, de ordem social, que inclui atitudes da família e de professores de Educação Física; de ordem ambiental, que engloba instituição especializada como o IBC, materiais adaptados e infraestrutura de centros de atividade física; e fatores de ordem pessoal, que incluem o reconhecimento dos benefícios da atividade física, sentimento de exclusão nas aulas de Educação Física, dificuldades nas habilidades espaciais e na coordenação motora.

De acordo com os resultados da presente pesquisa, dois fatores emergiram tanto na categoria "facilitadores", quanto na "barreiras". O primeiro diz respeito à família. Este importante elemento da sociedade deve estar sob a atenção de professores, pedagogos, psicólogos e outros profissionais que atendem adultos e crianças com cegueira. Considerando que a família pode assumir papéis distintos na vida da pessoa com deficiência visual, facilitando-a ou dificultando-a o acesso à prática física, é fundamental fornecer-lhe suporte necessário para a adoção de atitudes que incentivem, motivem e possibilitem às pessoas que não enxergam um estilo de vida mais ativo. 
O segundo fator diz respeito ao professor de Educação Física. Destaca-se a importância da qualificação destes profissionais no atendimento de seus alunos com cegueira. É fundamental que eles modifiquem e/ou adaptem atividades de modo a maximizar habilidades pautadas em canais táteis e auditivos de seus alunos. O professor pode valer-se de materiais e ambientes adaptados, elementos que tiveram destaque neste estudo como facilitador da prática física. Deste modo, seria possível proporcionar aos alunos com cegueira possibilidades para sua efetiva participação nas aulas de Educação Física, contribuindo para diminuir índices de patologias associadas ao estilo de vida sedentário e, sobretudo, para proporcionar-lhes diversidade em suas experiências corporais, importante para o desenvolvimento de uma imagem corporal integrada e positiva.

Além destes fatores, outra questão que deve ser destacada diz respeito à percepção dos participantes quanto à limitada infraestrutura de algumas academias de ginástica, que dificultam o livre acesso destes. Repensar em políticas de acessibilidade, tanto em ambientes públicos como em privados, é uma necessidade central no sentido de possibilitar às pessoas com cegueira usufruir de diferentes recintos propagadores de atividade física.

Finalmente, as questóes de ordem pessoal merecem destaque. O sentimento de exclusão experimentado na infância durante as aulas de Educação Física demonstra a importância de que políticas de integração no ambiente escolar sejam adotadas. $\mathrm{O}$ convívio harmônico, positivo e integrado com os colegas videntes pode favorecer, sobremaneira, o interesse pela prática da atividade física. Em adição, as dificuldades relatadas pelos participantes na coordenação motora e habilidades espaciais enfatizam a necessidade de que a atividade física tenha um lugar privilegiado durante o desenvolvimento destas pessoas, visto que esta é um importante elemento da aquisição destes tipos de habilidades.

Por conseguinte, sugere-se estudos futuros que explorem os facilitadores e barreiras percebidos por outros públicos de pessoas com deficiência visual, como aqueles com cegueira adquirida e baixa visão, ampliando a discussão nesta área, favorecendo, sobretudo, o acesso desta população a programas de atividade física.

\section{REFERÊNCIAS}

ADELSON, E.; FRAIBERG, S. Gross Motor Development in Infants Blind from Birth. Child Development., Malden, v. 45, p. 114-126, 1974.

ARDITI, A.; HOLTZMAN, J. D; KOSSLYN, S.M. Mental Imagery and Sensory Experience in Congenital Blindness. Neuropsychologia, Dallas, v. 26, p. 1-12, 1988.

ARDITO, M.; ROBERTS, J. J. A Catalog of Physical Activities for Visually Impaired Youth. Electronic Projects Collection, Worcester, p. 8-65, 2007.

BARDIN, L. Análise de conteúdo. Trad. Luís Antero Reto e Augusto Pinheiro. Lisboa: Ediçôes 70, 1977.

BATISTA C. G. Formação de conceitos em crianças cegas: questôes teóricas e implicaçóes educacionais. Psicologia: Teoria e Pesquisa, Brasília, v. 21, n. 1, p. 7-15, 2005.

BIGELOW A. E. Blind and sighted children's spatial knowledge of their home Environments. International Journal of Behavioral Development, Amsterdam, v. 19, n. 4, p. 797-816, 1996. 
BIGELOW, A. Spatial mapping of familiar locations in blind children. Journal of Visual Impairment and Blindness, New York, v. 85, n. 3, p. 113-117, 1991.

BRAMBRING, M. Divergent development of gross motor skills in children who are blind or sighted. Journal of Visual Impairment \& Blindness, New York, v. 100, n. 10, p. 620-634, 2006.

ÇOLAK, T., et al. Physical fitness level of blind and visually impaired goalball team players. Isokinetics and Exercise Science, Lansdale, v. 12, p. 247-252, 2004.

DE POTTER, J. C. The contribution of sport and physical activity to the-well-being of visually impaired people. Science \& Sports, Paris, v. 21, p. 249-250, 2006.

FIEHLER, K.; REUSCHEL, J; RÖSLER, F. Early non-visual experience influences proprioceptivespatial discrimination acuity in adulthood. Neuropsychologia, Dallas, v. 47, p. 897-906, 2009.

HOLBROOK, E. A. et al. Physical Activity, Body Composition, and Perceived Quality of Life of Adults with Visual Impairments. Journal of Visual Impairment \& Blindness, New York, v. 103, n. 1, p. 17-29, 2009.

JANSSEN, I.; LEBLANC, A. G. Systematic review of the health benefits of physical activity and fitness in school-aged children and youth. International Journal of Behavioral Nutrition and Physical Activity, London, v. 7, n. 40, p. 1-16, 2010.

KAKIYAMA, T.; KODA, Y.; MATSUDA, M. Effects of physical inactivity on aortic distensibility in visually impaired young men. European Journal of Applied Physiology, Heidelberg, v. 79, p. 205 - 211, 1999.

KOBBERLING, G. L.; JANKOWSKI, W.; LEGER, L. Energy cost of locomotion in blind adolescents. Adapted Phyisical Activity Quarterly, Champaign, v. 6, p. 58-67, 1989.

KOZUB, F.M.; OH, H. An exploratory study of physical activity levels in children and adolescents with visual impairments. Clinical Kinesiology, Monmouth, v. 58, n. 3, p. 1-7, 2004.

LAMBERT, R.; WEST, M. Parenting styles and the depressive syndrome in congenitally blind individuals. Journal of Visual Impairment \& Blindness, New York, v. 74, n. 9, p. 333 - 337, 1980.

LOPES, M. C. B.; KITADAI, S. P. S.; OKAI, L. A. Avaliação e tratamento fisioterapêutico das alteraçôes motoras presentes em crianças deficientes visuais. Revista Brasileira de Oftalmologia, Rio de Janeiro, v. 63, n. 3, p. 155-161, 2004.

MORGADO, F. F. R.; CAMPANA, A. N. N. B; TAVARES, M. C. G. C. F. Aplicabilidade do grupo focal com pessoas cegas. Benjamin Constant, Rio de Janeiro, v. 17, n. 52, p. 5-13, 2012.

MORRONGIELLO, B. A. et al. Spatial knowledge in blind and sighted children. Journal of Experimental Child Psychology, Boca Raton, v. 59, n. 2, p. 211-233, 1995.

MURPHY, F.M.; O'DRISCOLL, M. Observations on the motor development of visually impaired children: Interpretations from video recordings. Physiotherapy, Oxford, v. 75, n. 9, p. 505-508, 1989.

NOORDZIJ, M. L.; ZUIDHOEK, S.; POSTMA, A. The influence of visual experience on visual and spatial imagery. Perception, London, v. 36, p. 101-112, 2007.

OCHAITA, E.; ROSA, A. Percepção, ação e conhecimento nas crianças cegas. In: COLL, C.;

PALACIOS, J.; MARCHESI, A. (Orgs.). Desenvolvimento psicológico e educação. Porto Alegre: Artes Médicas, 1995.

PENEDO F.J.; DAHN J.R. Exercise and well-being: a review of mental and physical health benefits associated with physical activity. Current Opinion in Psychiatry, Pittsburgh, v. 18, n. 2, p.189-93, 2005. 
PLANINSEC, J.; PISOT, R. Motor coordination and intelligence level in adolescents. Adolescence, San Diego, v. 41, n. 164, p. 667-676, 2006.

PONCHILLIA, S. V. et al. The effectiveness of aerobic exercise instruction for totally. Journal of Visual Impairment \& Blindness, New York, v. 86, n. 4, p. 174-177, 1992.

RIMMER, J. et al. Physical activity participation among persons with disabilities: barriers and facilitators. American Journal of Preventive Medicine, San Diego, v. 26, n. 5, p. 419-425, 2004.

RIMMER, J. H. et al. Accessibility of health clubs for people with mobility disabilities and visual impairments. American Journal of Public Health, Washington, v. 95, n. 11, 2005.

SANTIN, S.; SIMMONS, J. N. Problems in the construction of reality in congenitally blind children. Journal of Visual Impairment \& Blindness, New York, v. 71, n. 10, p. 425 - 429, 1977.

SEABRA JÚNIOR, M. O.; MANZINI, E. J. Recursos e estratégias para o ensino do aluno com deficiência visual na atividade física adaptada. Marília: ABPEE, 2008.

SILVA, A. J.; DUARTE, E.; ALMEIDA, J. J. G. Campeonato escolar e deficiência visual: o discurso dos professores de educação física. Movimento, Rio Grande do Sul, v. 17, n. 02, p. 37-55, 2011.

SÖDERGREN, M. et al. Physical activity, exercise and self-rated health: a population-based study from Sweden. BMC Public Health, London, v. 8, n. 352, p. 1-9, 2008.

SOLER, R. Educação física inclusiva na escola em busca de uma escola plural. Rio de Janeiro: Sprint, 2005.

STUART, M. E.; LIEBERMAN, L.; HAND, K. E. Beliefs About Physical Activity Among Children Who Are Visually Impaired and Their Parents. Journal of Visual Impairment \& Blindness, New York, v. 100, n. 4, p. 223-234, 2006.

THINUS-BLANC, C.; GAUNET, F. Representation of space in blind persons: vision as a spatial sense? Psychological Bulletin, Berkeley, v. 121, n. 1, p. 20-42, 1997.

UNGAR, S.; BLADES, M.; SPENCER, C. The construction of cognitive maps by children with visual impairments, In: PORTUGALI, J. (Ed.). The Consruction of Cognitive Maps. Netherlands: Kluwer Academic Publishers, 1996.

VECCHI, T. Visuo-spatial imagery in congenitally totally blind people. Memory, London, v. 6, n. 1, p. 91-102, 1998.

WINNICK, J. P. Performance of visually impaired youngsters in physical education activities:

Implications for mainstreaming. Adapted Physical Activity Quarterly, Champaign, v. 3, p. 58-66, 1985.

Recebido em: 19/09/2012

Reformulado em: 16/04/2013

Aprovado em: 22/05/2013 
MORGADO, F. F. R. et al. 